\title{
THE THIRD MAN ARGUMENT IN THE PARMENIDES: REFLEXÕES SOBRE UM TEXTO SEMINAL
}

\section{Guilherme da Costa Assunção Cecílio*}

RESUMO: O artigo de Vlastos intitulado "The Third Man Argument in the Parmenides" é um marco nos estudos platônicos; neste o autor individuou duas premissas implícitas do argumento do Terceiro Homem, as quais têm relevantes consequências não apenas para o Parmênides, mas para a Teoria das Ideias como um todo. Este trabalho pretende discutir os principais aspectos da rica interpretação proposta por Vlastos no referido artigo.

PALAVRAS-CHAVE: ontologia; Teoria das Ideias; argumento do Terceiro Homem; autopredicação; não-identidade.

\section{THE THIRD MAN ARGUMENT IN THE PARMENIDES: REFLEXIONS ON A SEMINAL TEXT} the author individuated two implicit assumptions of the Third Man Argument, which have important consequences not only for the Parmenides, but for the Theory of Ideas as a whole.

KEYWORDS: ontology; Theory of Ideas; the Third Man argument; self-predication, nonidentity.

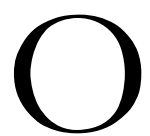
argumento do Terceiro Homem é talvez a mais célebre objeção à Teoria das Ideias. Sua história remonta ao próprio Parmênides de Platão, ${ }^{1}$ bem como à Metafísica aristotélica, ${ }^{2}$ percorrendo um longo caminho até os dias atuais. ${ }^{3} \mathrm{Na}$ história mais recente dos estudos platônicos houve um aumento de interesse tão notável por ele que um platonista se queixou do excesso de

\footnotetext{
${ }^{1}$ Parmênides 131e-132b e 132d-133a.

${ }^{2}$ Metafísica 990b15-17.

${ }^{3}$ Para um inventário da história do argumento do Terceiro Homem, cf. Cornford, 1939, p. 87-95.
}

* Mestre pelo

Programa de Pós-

Graduação em Lógica

e Metafísica da

Universidade Federal

do Rio de Janeiro. 
atenção dispensada a um único argumento. ${ }^{4}$ Seja como for, o marco dessa bibliografia contemporânea é o artigo de 1954 de autoria de Gregory Vlastos, intitulado "The Third Man Argument in the Parmenides". Neste foram introduzidos termos e conceitos que ate o presente momento continuam a alimentar a exegese dos textos de Platão, e, em particular, de sua Teoria das Ideias. O próprio Vlastos ocupou-se por muito tempo com as questões levantadas no referido artigo: dedicou-lhe adendos, ${ }^{5}$ bem como, anos mais tarde, publicou um novo artigo acerca do Terceiro Homem. ${ }^{6}$ A influência das questões surgidas nesse primeiro texto de 1954 pode ser sentida também em muitos outros de seus artigos que, entretanto, não tratam do Parmênides. Por todas essas razões, parece-nos interessante voltar a atenção para esse texto seminal.

Vlastos, no começo de seu artigo de 1954, estabelece como meta dar resposta a estas duas questões: "Is the Third Man Argument a valid objection to the Theory of Forms? Did Plato believe that it was valid?"

Trata-se, na verdade, de dois objetivos bastante distintos. Por um lado, o autor deseja determinar se o argumento constitui uma dificuldade efetiva à Teoria das Ideias, isto é, se se trata de um entrave objetivo a essa teoria; nesse sentido, a perspectiva de Vlastos é bastante geral: trata-se de decidir se um determinado argumento é compatível ou não com determinada doutrina. Por outro lado, ele também se ocupa da economia interna do Parmênides, e pretende mesmo determinar se Platão, subjetivamente considerado, acreditava na força do Terceiro Homem. ${ }^{8}$

Antes de abordar propriamente o conteúdo do artigo, convém refletir acerca do primeiro dos referidos objetivos. ${ }^{9}$ Que é preciso para responder convincentemente se o Terceiro Homem é uma boa objeção à Teoria das Ideias? Parece-nos que três passos são necessários.

Antes de tudo, compreender bem o Terceiro Homem tal como ele foi redigido por Platão, e com que "tipo" de Teoria das Ideias o argumento se compromete. Não resta dúvida que o argumento lida com certa Teoria das Ideias; é preciso investigar, porém, as peculiaridades da teoria aí veiculadas.

\footnotetext{
${ }^{4}$ Sayre, 2005, p.276, n 23: "No commentator [...] should be content with the disproportionate attention given the 'third man' argument in recent literature".

${ }^{5}$ Vlastos, 1955; Vlastos, 1956.

${ }^{6}$ Vlastos, 1969, reeditado com pequenas alterações em Vlastos, 1981.

${ }^{7}$ Vlastos, 1954, p. 319.

${ }^{8}$ Vlastos é bastante enfático no aspecto subjetivo, quase psicológico, da questão; a famosa expressão cunhada no artigo, the record of honest perplexity, atesta-o. Duma forma ou de outra, Vlastos se envolve na questão que atraiu a atenção de tantos leitores de Platão. Trata-se de procurar elucidar o lugar do Parmênides no corpus platonicum. O enigma hermenêutico que esse diálogo nos apresenta pode ser resumido na seguinte pergunta: porque Platão redigiu críticas tão duras ao que parece ser o cerne de sua filosofia, a sua própria teoria ontológica?

${ }^{9}$ Quanto ao segundo objetivo do artigo, podemos deixá-lo por ora em segundo plano, já que na própria opinião de Vlastos ele é condicionado pelo primeiro.
} 
Em segundo lugar, é indispensável determinar o que seja a versão padrão, standard, da Teoria das Ideias, aquela que se poderia atribuir com segurança a Platão.

Por fim, é preciso comparar ambas as versões, a standard e a veiculada no Terceiro Homem, a ver se elas coincidem. Se for esse o caso, determinadas consequências poderiam ser aduzidas já no âmbito geral da Teoria das Ideias. ${ }^{10}$

Essas três etapas constituem efetivamente a estrutura do artigo de Vlastos. ${ }^{11} \mathrm{E}$, como já sabemos, a conclusão a que ele chega é que o Terceiro Homem é uma fabulosa objeção à Teoria das Ideias, isto é, não apenas à Teoria das Ideias com a qual o argumento está comprometido, mas à Teoria das Ideias standard. ${ }^{12} \mathrm{E}$ essa será a resposta à primeira das questões enunciadas no começo de seu artigo.

O texto de Vlastos depende da análise do seguinte trecho do Parmênides:

Creio que tu crês que cada forma é uma pelo seguinte: quando algumas coisas, múltiplas, te parecem ser grandes, talvez te pareça, a ti que as olhas todas haver uma certa ideia uma e a mesma em todas; donde acreditas o grande ser um.

Dizes a verdade, disse ele.

Mas... e quanto ao grande mesmo e às outras coisas grandes? Se olhares da mesma maneira, com a alma, para todos esses, não aparecerá, de novo, um grande, um, em virtude do qual é necessário todas aquelas coisas aparecerem como grandes?

Parece que sim.

Logo, uma outra forma de grandeza aparecerá, surgindo ao lado da grandeza mesma e das coisas que desta participam. E, sobre todas essas, aparecerá de novo outra, de modo a, em virtude dela, todas essas parecerem grandes. E não mais será uma cada uma das tuas formas, mas ilimitadas em quantidade. ${ }^{13}$

Vlastos propõe que o argumento seja transcrito como segue:

\footnotetext{
${ }^{10}$ Essas três etapas se revelam, tão logo se as considere com suficiente sobriedade, muito complexas; demonstrá-las satisfatoriamente exigiria um trabalho de considerável extensão. No que se refere, por exemplo, à determinação da versão standard da Teoria das Ideias, os problemas são múltiplos: pode haver quem se recuse a sequer usar a expressão "Teoria das Ideias", para já não mencionar as dificuldades de se precisar o que seria o núcleo bona fide da teoria. É, portanto, evidente que de um artigo de poucas páginas não se pode exigir um sucesso total, uma "demonstração" exaustiva de todas as etapas requeridas para seu objetivo.

${ }^{11} \mathrm{O}$ que se vê na própria divisão do artigo em "I. ANALYSIS OF THE ARGUMENT", que diz respeito à primeira etapa, e "II. THE ASSUMPTIONS OF THE ARGUMENT AND THE THEORY OF FORMS", que procura dar conta da segunda e terceira etapas.

${ }^{12}$ A estratégia de Vlastos, bastante simples e clara, envolve mostrar que a "versão" da teoria presente no Terceiro Homem nada mais é do que a genuína Teoria das Ideias.

${ }^{13}$ Platão, 2003, p.37. Tradução Maura Iglésias e Fernando Rodrigues.
} 
$\left(A_{1}\right)$ Se várias coisas a, b e c são todas F, então deve haver uma única Forma F-dade em virtude da qual apreendemos a, b e c como sendo $\mathrm{F}^{14}$

$\left(A_{2}\right)$ Se a, b, c e F-dade são F, então deve haver outra Forma F-dade ${ }_{1}$, em virtude da qual apreendemos a, b, c e F-dade como sendo F. ${ }^{15}$

Vlastos chama atenção para o fato de que tal como o argumento está formulado, $\mathrm{A}_{2}$ não segue de $A_{1}$; e uma vez que temos um non sequitur, o regresso infinito, a rigor, sequer chega a se instaurar. Para que o argumento possa "funcionar", são necessárias outras premissas, as quais são eventualmente supridas pelo leitor. Vlastos afirma, porém, a importância de que se as explicite. A primeira delas seria:

$\left(\mathrm{A}_{3}\right)$ Qualquer Forma pode ser predicada de si mesma: F-dade é F. ${ }^{16}$

Ele atribui o mérito da descoberta dessa premissa a A. E. Taylor, ${ }^{17}$ a qual Vlastos chama de premissa da autopredicação. Uma vez que $A_{2}$ é um condicional, a função de $A_{3}$ é tornar verdadeiro o antecedente de $\mathrm{A}_{2}$. Mas mesmo assim o argumento não está completo; ainda falta a premissa da não-identidade, a qual Vlastos crê ter sido o primeiro a individuar. ${ }^{18}$ $\left(\mathrm{A}_{4}\right)$ Se algo possui certa característica, esse algo não pode ser idêntico à Forma em virtude da qual nós apreendemos essa característica: Se x é F, x não pode ser idêntico a F-dade. ${ }^{19}$

$\mathrm{O}$ papel de $\mathrm{A}_{4}$ é tão trivial quanto fundamental: justificar a passagem, em $\mathrm{A}_{2}$, do antecedente ao consequente.

O tipo de análise que Vlastos leva a cabo com a simples explicitação dessas premissas é, sem dúvida, penetrante e original. Por outro lado, seu artigo não consiste apenas no esclarecimento duma formulação supostamente imprecisa e truncada; por mais incompleta que seja a formulação de Platão, o argumento sempre foi compreendido por seus leitores, que duma forma ou de outra acabam suprindo essas premissas. O surpreendente e peculiar da análise de Vlastos é que ele pretende mostrar que a explicitação de tais premissas traz à luz uma contradição no sentido forte do termo.

$A_{3}$, a premissa da autopredicação, nos dá que $F$-dade é $F$. $A_{4}$ reza que se x é $F$, x não é idêntico a F-dade. Basta que se substitua a variável x por F-dade, que teremos:

$\left(\mathrm{A}_{5}\right)$ Se F-dade é F, F-dade não pode ser idêntico a F-dade. ${ }^{20}$

Ora, já sabemos por $\mathrm{A}_{3}$ que F-dade é F; conclui-se, pois, que F-dade não é idêntico a F-dade.

\footnotetext{
${ }^{14}$ Vlastos, 1954, p. 320.

${ }^{15}$ Ibid., p. 321.

${ }^{16}$ Ibid., p. 324.

${ }^{17}$ Vlastos 1954, p. 324, n.8.

${ }^{18}$ Ibid., p. 325.

${ }^{19} \mathrm{Idem}$.

${ }^{20}$ Ibid., p. 326.
} 
Se se der crédito a tal conclusão, a compreensão tradicional do argumento como um regressus cai por terra. A ameaça apresentada pelo Terceiro Homem revelar-se-ia mais temível do que jamais se supôs: tratar-se-ia dum argumento inconsistente, que implicaria que toda Forma seria não idêntica a si mesma, isto é, $\mathrm{x}$ seria diferente de $\mathrm{x}$, suprema contradição ${ }^{21}$. A Lógica nos ensina que dum argumento inconsistente qualquer conclusão pode seguir; e, como já insinua Vlastos, se a própria Teoria das Ideias está comprometida com essas premissas, também ela correria o risco de se tornar uma teoria banal.

$\mathrm{Na}$ verdade, o novo perfil que Vlastos pretendeu conferir ao argumento não se sustenta: o argumento não abriga a contradição "F-dade não é idêntico a F-dade". Vejamos por quê.

A formulação vlastosiana de $\mathrm{A}_{4}$, a premissa da não-identidade, definitivamente não é uma expressão adequada do "dispositivo" envolvido no Parmênides. Tudo o que se pode extrair com segurança do texto platônico é a necessidade de se postular uma nova Forma para que se dê conta duma multiplicidade de indivíduos que passa a incluir (seja, como quer Vlastos, via autopredicação) as próprias Formas.

O melhor seria reformular o princípio de não-identidade, e uma expressão menos ambígua seria a seguinte: "Se x é F, x não coincide com $\mathrm{Q}$, 国 Forma em virtude da qual x é F." Teríamos, nesse caso, três variáveis: a variável $\mathrm{x}$, cujo escopo é constituído pelos indivíduos que possuem determinada característica (ou propriedade); a variável $\mathrm{F}$, que justamente responde por essa característica; e a variável $\square$, que aponta para a Forma que é responsável pela característica $\mathrm{F}^{22}$ Sendo assim, mesmo no caso crítico em que se aceita como substituto da variável x a própria Forma F-dade, nesse exato momento o substituto da variável $\square$, já

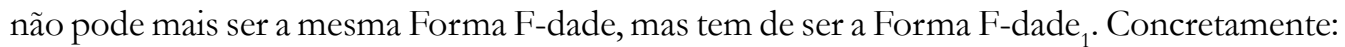
"Se F-dade é F, F-dade não coincide com F-dade, , a Forma em virtude da qual F-dade é F"; dissolve-se assim qualquer contradição do tipo F-dade $\neq$ F-dade.

Como já deve estar suficientemente claro, tudo que é lícito extrair do texto do Parmênides é que para dar conta do fato de que a própria Forma F-dade possua a característica F (o que consistiria na autopredicação) é necessário supor uma nova Forma, seja F-dade, , e assim sucessivamente. Ora, que dizer dessa conclusão? Tudo que temos é que o argumento

${ }^{21}$ Tal contradição teria sido trazida à luz somente no próprio artigo de Vlastos, que, desse modo, pretende explicar a verdadeira "natureza" do argumento; Idem: "[...] and their inconsistency does not need to be exposed through the indirect and elaborate machinery of the infinite regress, but can be shown much more simply and directly".

${ }^{22}$ Quando Vlastos exprime o princípio de não-identidade em linguagem natural, ele parece estar muito próximo da estrutura efetivamente presente no texto de Platão: algo, contudo, se perdeu na "formalização". O que, em nossa opinião, se perdeu foi a presença de outra variável, a qual procuramos suprir com a variável $\square$. Comparar, a esse propósito, o modo como Vlastos exprimiu $\mathrm{A}_{4}$ (Vlastos, 1954, p. 325): "If anything has a certain character, it cannot be identical with the Form in virtue of which we apprehend that character. If $x$ is F, $x$ cannot be identical with F-ness"; grifo nosso. 
é exatamente aquilo que sempre se pensou que ele fosse: regressus ad infinitum, e não uma fatal contradição. ${ }^{23}$

Voltemos agora ao artigo de Vlastos de 1954. Como se sabe, existem duas versões do Terceiro Homem no Parmênides. O autor passa a analisar a segunda versão, procurando mostrar que ela mobiliza essencialmente os mesmos passos lógicos que a primeira. Vejamos mais uma vez o próprio texto de Platão:

[...] mas, Parmênides, a mim está sendo evidente que o que se passa é, antes, o seguinte: que estas formas estão na natureza como paradigmas, e que as outras coisas se parecem com elas e são semelhanças delas. E que essa participação nas formas, para estas outras coisas, não vem a ser senão o serem estas feitas como imagens daquelas.

Se, então, algo se parece com a forma, disse Parmênides, é possível essa forma não ser semelhante àquilo que é feito como sua imagem, na medida em que esta foi feita semelhante a ela? Ou será que há um meio de o semelhante não ser semelhante ao semelhante?

Não há.

Mas será que não é fortemente necessário o semelhante participar da mesma coisa uma que seu semelhante?

É necessário sim.

Aquilo de que, participando, as coisas semelhantes serão semelhantes, não será a forma mesma?

Absolutamente sim. Logo, não é possível algo ser semelhante à forma, nem a forma a outra coisa. Senão, ao lado da forma, sempre aparecerá outra forma, e se esta for semelhante a algo, aparecerá de novo outra, e nunca cessará de surgir sempre uma nova forma, se a forma for semelhante ao que dela participa. ${ }^{24}$

Vlastos associa essa versão do argumento a Copy-Theory, um termo cunhado para designar um certo esquema interpretativo do tema da relação sensível-inteligível em Platão. ${ }^{25}$ Segundo Vlastos, a diferença entre a primeira e a segunda versão dos argumentos seria que a

\footnotetext{
${ }^{23}$ Por fim, o próprio Vlastos também atingiu esta conclusão, quando num artigo posterior, "Plato's 'Third Man'Argument (Parm.132A1-B2): Text and Logic", publicado em 1969 e reeditado em 1981, ele admite que sua formalização do argumento no artigo de 1954 havia sido falha, de modo que a contradição obtida não emergia do Parmênides, mas sim de sua própria fórmula. Na reedição desse artigo, lê-se esta nova nota (Vlastos, 1981, p. 352, n. 40): "Due to my defective axiomatization of Plato's argument in TMA I, I had inferred that SP and NI are an inconsistent pair. This they are not when formulated as above." A nova formulação a que Vlastos faz referência encontra-se na reedição do artigo (Vlastos, 1981, p. 363-365, APPENDIX II). ${ }^{24}$ Platão, 2003, p.39.

${ }^{25}$ Vlastos, 1954, p. 331-332.
} 
linguagem em que esta última é expressa, isto é, a linguagem da Copy-Theory, tornaria "quase" explícitos os dois princípios tão caros à sua interpretação. ${ }^{26}$

No que concerne à autopredicação, ela decorreria da noção de semelhança. Se a relação entre coisas sensíveis que possuem a característica F e certa Ideia é uma relação de semelhança, é evidente que também a Ideia tem de possuir a característica F (autopredicação); se assim não fosse, como poderia haver semelhança? ${ }^{27}$

Analogamente, a Copy-Theory tornaria "quase" patente o princípio de não-identidade: a própria distinção fundamental entre o paradigma e as coisas que se assemelham a esse paradigma já implicaria a não-identidade dos termos em questão.

Sendo assim, teríamos a mesma estrutura, com as mesmas premissas implícitas, redundando nas mesmas conclusões já analisadas com respeito à primeira versão do argumento. Nessa altura Vlastos reafirma sua posição:

If Plato knew that his theory commits him to these premises, he would not need the regress to tell him that his theory is logically moribund and must submit to drastic surgery to survive. ${ }^{28}$

Semelhante conclusão é, sem dúvida, grave. Mas, como já referimos acima, ela só se sustenta se Vlastos conseguir mostrar que a autêntica Teoria das Ideias está de fato comprometida com these premises. Por outro lado, segundo o próprio autor, essas premissas não são nada mais do que premissas implícitas no argumento: é, portanto, perfeitamente cabível ao menos questionar se elas constituem princípios bona fide da Teoria das Ideias. Caso não, todos os problemas associados ao Terceiro Homem teriam de ser bastante redimensionados; isto é, seja se se compreende o argumento como uma fatal contradição, seja se se o compreende como um regressus, em ambos os casos ele seria inofensivo à Teoria das Ideias.

A segunda parte do artigo enfrenta este problema: se a Teoria das Ideias presente no argumento do Terceiro Homem é a autêntica Teoria das Ideias. ${ }^{29}$

Depois duma sumária apresentação da ontologia de Platão, ${ }^{30}$ Vlastos passa a investigar, em primeiro lugar, se a autopredicação faz parte de tal ontologia.

\footnotetext{
${ }^{26}$ Vlastos, 1954, p. 331. "It is worth noting that the two Assumptions of Self-Predication and (full-strength) Nonidentity which are still necessary, as they were in the first version, are still tacit, for neither of them is stated as such; but they are now much closer to the verbal surface of the Argument, for they are both logically implied and even intuitively suggested by the key-concept of the second version, the Copy-Theory of participation."

${ }^{27}$ A noção de semelhança desempenharia a função de apontar para determinada característica F que o sensível, em primeiro lugar, possuiria; de acordo com a Copy-Theory, as Ideias seriam os paradigmas dessa característica $\mathrm{F}$, possuindo, por conseguinte, também elas a característica $\mathrm{F}$.

${ }^{28}$ Vlastos, 1954, p. 332.

${ }^{29}$ Ibid., p. 336. "We can now ask. whether this ontology does or does not include the two tacit premises of the Third Man Argument."

${ }^{30}$ Vlastos parte do aspecto que lhe parece central: a separação. Que significaria, afinal, para Platão a separação? O tema que lhe parece intrinsecamente associado à separação é o ser; as Ideias são separadas porque são em sentido pleno, ao passo que o sensível não é em sentido pleno (isso se é
} 
Vlastos reconhece não haver nenhuma defesa explícita da autopredicação. Mas isso não significaria, segundo ele, que não haja qualquer prova para ela; a autopredicação poderia ser rastreada por dois modos diferentes. Por um lado, ela seria a consequência (implícita) que pode ser deduzida de algumas teorias platônicas. Por outro lado, ela mostrar-se-ia em algumas referências alusivas, por vezes até casuais. ${ }^{31}$

No tocante às supostas ocorrências textuais, ele menciona, sem se deter, Líside $217 \mathrm{~d}$, no qual haveria uma referência (mais ou menos implícita) à própria Brancura ser branca. Exemplos mais convincentes seriam os do Prótagoras 330c-d, e Fedão 100c, bem como os do Banquete, que embora jamais afirme claramente que a Beleza seja bela, isso está suposto no discurso de Diotima como um todo. ${ }^{32}$

que se pode dizer do sensível que ele de alguma forma seja). Obviamente enunciar essa inter-relação não resolve o problema, mas só o complica: afinal, qual o significado de ser para Platão? Vlastos aborda uma questão tão complexa, provavelmente a questão mais complexa que se pode colocar com respeito à Teoria das Ideias, de modo surpreendentemente breve. Ele distingue quatro características que Platão teria atribuído ao ser das Ideias, e afirma que Platão, ao contrário do que Aristóteles fará, não promoveu uma investigação dos diversos sentidos de ser, mas simplesmente considerava todos esses sentidos ou modos de ser inevitavelmente unidos. Esta é a enumeração (Ibid., p. 334): “(i) x is intelligible; (ii) $x$ is changeless; (iii) $x$ is not qualified by contrary predicates; (iv) $x$ is itself the perfect instance of the property of relation which the word for ' $x$ ' connotes.". Para ele não é problemático atribuir os três primeiros tópicos à ontologia platônica; ele fornece, inclusive, em nota a referência textual. Mas é somente o quarto tópico que implica a autopredicação; contudo, para esse caso não é tão simples fornecer bases textuais suficientes.

${ }^{31}$ Ibid., p. 336-337. "But if he never stated it, what reason can be given for saying that he did make it after all?The reason is that it is certainly implied by various things he said and believed. It is implied, first of all, both by his Degrees-of-Reality Theory and by his Copy-Theory of the relation of things to Forms. For if an F particular is only "deficiently" F, and only the corresponding Form is perfectly F, then F-ness is F. Or if the F particular is a copy of F-ness and resembles F-ness in respect of being F, then, once again, F-ness is F. Moreover, Self-Predication is also implied by quite a different set of statements which are not elucidations of the Theory of Forms, but direct and, at times, casual assertions about this or that Form".

${ }^{32}$ Ibid., p. 337-338. "When a man's hairs have turned white, says Socrates in the Lysis (2I7d), "they have become such as that which is present in them, white through Whiteness": the white hairs are "such as" or "of the same quality as" [...] Whiteness; they have the same quality that Whiteness has. Somewhat later, in the Protagoras (330c-d) we get an even more striking text which [...] has become the star instance of Self-Predication in Plato. Here Socrates roundly declares that justice is just and holiness holy. "What other thing could be boly, if holiness isn't holy," he askes, indignant at the idea that anyone could gainsay that holiness is holy. [...] In the Phaedo (100c) Socrates gives away the same presumption when he indulges in the expression, "If anything else is beautiful, besides Beanty itself." And in the Symposium, while there is no one sentence that says quite baldly that Beanty is beautiful, the whole point of Diotima's speech is that the Form of Beauty is superlatively fair, incomparably more so than fair bodies, minds, or institutions: the universal enters into competition with its instances, and has no trouble at all winning the beauty contest." Sobre essas "ocorrências" da autopredicação se debruçaram muitos comentadores que vieram depois de Vlastos. O próprio Vlastos retomou, no seu artigo "The Unity of the Virtues in the Protagoras", a passagem que considerara the star instance of Self-Predication in Plato, para propor uma maneira inteiramente nova de entender proposições prima facie autopredicativas, nomeadamente, a predicação paulina. Vlastos, 
Vlastos apresenta outros argumentos para sustentar sua posição. Ele traz à baila o fato linguístico de que uma Ideia não precisa ser expressa por um substantivo abstrato, mas frequentemente o é por um termo adjetivo; assim Platão pode afirmar tanto que "a Justiça é justa" quanto que "o Justo é justo"; essa última formulação poderia tão facilmente ser tomada por uma tautologia, e, portanto, uma verdade incontestável, que a autopredicação poderia parecer algo muito mais natural do que de fato ela é. ${ }^{33}$

Dito isso, Vlastos volta a atenção para o princípio de não-identidade. Este seria trivial na filosofia de Platão: as Ideias são diferentes, isto é, não idênticas às coisas sensíveis; contudo, as Ideias são responsáveis pelas propriedades do sensível. Vlastos defende que Platão teria sido o primeiro a insistir na diferença entre determinada propriedade e as coisas que possuem essa propriedade, isto é, o primeiro a chamar a atenção para a realidade dos universais. Mas na versão de Vlastos, isto é, uma vez admitida a autopredicação das Ideias, o que distingue as Ideias e as coisas sensíveis que possuem a característica a ela associada é meramente uma diferença "quantitativa"; a diferença entre a Ideia de Beleza e uma coisa bela sensível consiste no fato que a Ideia de Beleza é sumamente bela. Não se trata duma diferença entre dois tipos diferentes de entes, mas sim de diferentes graus do mesmo tipo de ente. ${ }^{34}$

Aliás, essa não é nem sequer a única consequência indesejável da autopredicação. Como compreender a autopredicação quando referida a Ideias como a Justiça? Como pode a Justiça ser justa, se a Justiça não é um agente moral ${ }^{35}$ Ou como pode a Ideia de Movimento estar em movimento, se as Ideias são imutáveis? ${ }^{36} \mathrm{E}$ dificuldades como essas podem ser multiplicadas à exaustão. Note-se bem: Vlastos afirma que a autopredicação das Ideias é algo absurdo que, todavia, Platão teria sustentado. Como explicar, então, que Platão não se tenha dado conta das dificuldades decorrentes da autopredicação? A resposta de Vlastos é que ele não poderia percebê-las porque sequer tinha consciência do próprio princípio da

seguidamente, defendeu a existência desse tipo de predicação em outros contextos dialógicos, inclusive no Sofista (Cf. Vlastos, 1981, p. 270-322 e 404-409).

${ }^{33}$ Ibid., p. 338-339.

${ }^{34}$ Ibid., p. 340: "If the Form is what we have seen it to be, how could it help being other than the particulars whose characters it enables us to discern? Indeed, it might be said that Plato is the first Western thinker to make the distinction between a character and the things that have that character a matter of philosophical reflection. For did not bis Theory of Forms call attention, and for the first time, to the 'reality' of universals as distinct from that of material existents? This is, of course, perfectly true. But what is no less true is that the Platonic ontology inadvertently blurs the very distinction it was devised to express. It compels Plato to think of the difference between empirical existents and their intelligible properties as a difference between "deficiently" real and perfectly real things, i.e., as a difference in degree between beings of the same kind, instead of a difference in kind between different kinds of being. To say that the difference between a white thing, like wool or snow, and the universal, Whiteness, is a difference in degree of reality, is to put Whiteness in the same class with white things, albeit as a pre-eminent member of that class, endowed in preeminent degree with the character which its fellow members possess in variously deficient degrees; it is to think of Whiteness as a (superlatively) white thing, and thus to assimilate it categorically to white things, instead of so distinguishing it from them".

${ }^{35}$ Ibid., p. 337, n.33.

${ }^{36}$ Ibid., p. 339. 
autopredicação. Vlastos aventa mesmo a possibilidade de que Platão pudesse ter defendido esse princípio apenas oralmente; mas também esse não poderia ter sido o caso, senão Aristóteles certamente não teria perdido a oportunidade de explorar o potencial polêmico dessa doutrina, e nos teria relatado que Platão a defendera. ${ }^{37}$

Vlastos, contudo, já se mostra convencido de que a autopredicação pertença ao quadro da ontologia de Platão, de maneira que ele passa a analisar pretensas evidências textuais presentes no próprio Parmênides. Ele observa, aliás com bastante perspicácia, que muitas das aporias desse diálogo dependem da autopredicação; por exemplo, a questão da divisibilidade da Ideia de Grandeza em partes menores, que seriam então menores que a própria Grandeza (131c-d), ${ }^{38}$ e também a passagem das Ideias de Senhor e de Escravo (133b-134e), que possuiriam as "exatas" propriedades do senhorio e da escravidão, em contraste com um senhor e um escravo sensíveis. ${ }^{39}$

Em suma, na opinião de Vlastos, os princípios que Platão tacitamente admite, o próprio Platão teria de recusá-los se deles tivesse adquirido consciência; isso, contudo, haveria alterado substancialmente a sua ontologia. ${ }^{40}$

Admitamos por ora que ele tenha conseguido provar o que desejava. Que tipo de resultado nós deveríamos afrontar? Justamente o que já se mencionou: a ontologia de Platão, que seria também a ontologia presente no argumento do Terceiro Homem, estaria ameaçada, ameaça exemplarmente sintetizada nesse mesmo argumento.

Ainda que se afaste a interpretação de que haja uma contradição implicada no argumento do Terceiro Homem, o regressus nele presente é uma dificuldade poderosa. E tal dificuldade sai da própria pena de Platão, que, por outro lado, jamais redigiu a sua refutação. Por que, então, escreveu ele uma objeção que não apenas não respondeu, mas que para responder seria preciso abdicar de sua própria ontologia? A resposta de Vlastos é já famosa: trata-se do registro duma sincera perplexidade, the record of honest perplexity. ${ }^{41}$

$\mathrm{O}$ autor arrisca-se a fazer um esboço da "história intelectual" de Platão. ${ }^{42} \mathrm{O}$ filósofo teria inicialmente gozado da satisfação que os primeiros sucessos da Teoria das Ideias the proporcionaram; semelhante estado de espírito estaria presente na composição de obras como o Fedão, o Banquete e a República. Mais tarde, percebendo as dificuldades que pululavam, teria escrito o Parmênides, diálogo em que corajosamente preferiu não suprimir as aporias de sua própria teoria ontológica.

\footnotetext{
${ }^{37}$ Idem.

${ }^{38}$ Ibid., p. 345: " Suppose you divide Largeness itself, and each of the many large things is then large by virtue of a portion of Largeness which is smaller than Largeness itself...' (131c-d). To say that a 'part' of the Form, Largeness, is smaller than Largeness is most certainly to imply that Largeness is large".

${ }^{39}$ Ibid., p. 346-347.

${ }^{40}$ Ibid., p. 323. "He was thus holding consciously a metaphysical Theory whose disastrous implications were hidden from his conscious mind".

${ }^{41}$ Vlastos, 1954, p. 343.

${ }^{42}$ Vlastos, 1954, p. 343-344.
} 
Finalmente, a segunda questão levantada por Vlastos no começo de seu artigo pode encontrar resposta: acreditava Platão que o Terceiro Homem fosse uma objeção válida à Teoria das Ideias? A resposta é sim. Mas, deve-se notar, essa crença é marcada pela perplexidade; ele julgava-a poderosa, mas não podia mensurar toda a sua força pelos motivos já mencionados.

Terminada a exposição do argumento, voltemo-nos agora a sua apreciação. Cabem algumas críticas a Vlastos, ou melhor, ao artigo que analisamos, uma vez que o próprio Vlastos posteriormente reviu muitas de suas posições.

Em primeiro lugar, o autor supôs que o Terceiro Homem fosse uma objeção mais grave do que ela realmente é, na medida em que viu nela uma contradição stricto sensu. E como ele supõe que a própria Teoria das Ideias está em xeque no Terceiro Homem, ela se transforma numa teoria inconsistente.

Ademais, no que concerne à autopredicação, Vlastos passa muito rapidamente dum conjunto de sinais bastante problemáticos, para a certeza de que a autopredicação faça parte da autêntica Teoria das Ideias. É verdade que a Teoria das Ideias não é, por princípio, incompatível com a autopredicação; mas os argumentos de Vlastos não são decisivos. Poderse-iam levantar objeções a cada "prova" da autopredicação apresentada por Vlastos. ${ }^{43}$

Vlastos, baseado no que chamou de Copy-Theory, pretende deduzir que a Ideia seja autopredicável, uma vez que ela desempenharia o papel de modelo dum grupo de coisas sensíveis, suas imagens. Mas se poderia questionar semelhante ilação: a referida estrutura é tão claramente metafórica que parece ilícito extrair dela conclusões precisas, tal como a autopredicação.

A única referência textual clara para a autopredicação, Protágoras 330c-d, pode ser redimensionada de vários modos; seria possível, inclusive, argumentar que Platão tenha alterado posteriormente essa posição, apelando assim para a cronologia dos diálogos. ${ }^{44}$

Quanto às supostas referências à autopredicação contidas no próprio Parmênides, por mais penetrantes que sejam as análises de Vlastos, poder-se-ia contra-argumentar que o Parmênides não é o diálogo adequado para servir como prova da Teoria das Ideias standard; bem ao contrário, trata-se de sua instância crítica e problemática, de modo que se poderia sustentar que é justamente em razão da adoção da autopredicação que o jovem Sócrates acaba enredado em aporias.

Em suma, ao analisar a ontologia de Platão, Vlastos não atingiu seu desiderato, a saber, provar definitivamente que o princípio da autopredicação integre essa ontologia. Ele,

\footnotetext{
${ }^{43}$ Os argumentos aqui mencionados não são mais do que um esboço de verdadeiras objeções; eles devem servir para mostrar a fragilidade dos argumentos de Vlastos em favor da autopredicação neste artigo de 1954. É evidente que refutar a autopredicação (bem como defendê-la) de modo satisfatório exigiria um esforço que excede completamente o intuito do presente trabalho.

${ }^{44}$ Para uma refutação do próprio Vlastos à leitura autopredicativa dessa passagem, Cf. "The Unity of the Virtues in the Protagoras" (Vlastos, 1981, p. 221-265).
} 
contudo, mostrou a importância dessa questão, que ainda não parece resolvida entre os comentadores. $^{45}$

Muitas são também as virtudes desse artigo de 1954. Em primeiro lugar, Vlastos teve o enorme mérito de se dedicar detidamente à elucidação da estrutura lógica do texto; seu cuidado com o argumento trouxe à luz problemas que antes haviam sido eclipsados: ele mostrou que o argumento simplesmente não funciona sem determinadas premissas, e a explicitação dessas premissas foi sem dúvida um marco nos estudos recentes sobre Platão. Além disso, Vlastos conseguiu relacionar as premissas lógicas relativamente áridas do argumento do Terceiro Homem com os princípios ontológicos da Teoria das Ideias. Por isso não se trata duma questão vazia, dum virtuosismo lógico; trata-se de entender melhor a ontologia de Platão. ${ }^{46}$

Um dos aspectos mais interessantes do artigo é que ele consiste numa tomada de posição frente ao enigma que o Parmênides nos coloca. Como compreender as críticas aí presentes? A solução de Vlastos, the record of honest perplexity, é apenas o coerente resultado de suas premissas. A conclusão psicológica acerca do estado de espírito de Platão ao redigir o argumento, por mais que possa nos causar estranhamento, é uma tentativa de explicar como o filósofo poderia redigir críticas insuperáveis (na opinião de Vlastos) à sua própria teoria ontológica sem jamais chegar a abandoná-la.

A verdadeira força do artigo de Vlastos não reside na sua conjectura acerca dos motivos de composição do diálogo Parmênides e do argumento do Terceiro Homem, mas sim no estabelecimento das condições necessárias para avaliar o seu significado para a Teoria das Ideias. E na medida em que ele identificou, com grande perspicácia e originalidade, os princípios envolvidos no argumento, ele de fato trouxe à luz as condições de resolução do problema. ${ }^{47}$ Cabe aos intérpretes interessados na ontologia de Platão, e na relação do Parmênides com ela, completar o trabalho esboçado nesse pequeno artigo.

\footnotetext{
${ }^{45}$ Para um ótimo inventário crítico dos comentadores que adotaram uma ou outra posição, Cf. Fronterotta 2001.

${ }^{46}$ Como Vlastos lucidamente mostrou, aceitar irrestritamente a autopredicação das Ideias acaba por alterar significativamente a face da Teoria das Ideias; se tanto a Forma F-dade quanto os particulares sensíveis possuem uma característica $\mathrm{F}$, ao menos do ponto de vista da posse de $\mathrm{F}$, a diferença entre Ideias e indivíduos sensíveis só pode ser de grau. Não parece um acaso que a partir do artigo de Vlastos uma interpretação das Ideias como indivíduos perfeitos, paradigmas, tenha tomado força.

${ }^{47}$ Essas condições são, como já referimos, três: (1) individuar o tipo de ontologia presente no Terceiro Homem; (2) estabelecer a ontologia padrão de Platão; (3) verificar se a ontologia do Terceiro Homem é fundamentalmente a ontologia padrão de Platão. O primeiro passo foi levado a cabo por Vlastos com bastante sucesso. Os demais passos receberam um impulso inicial nesse artigo.
} 


\section{REFERÊNCIAS}

\section{Textos antigos}

ARISTOTELIS Metaphysica. Recognovit brevique adnotatione critica instruxit W. Jaeger, col.: "Oxford Classical Texts". Oxford: Oxford University Press, 1957.

PLATONIS Opera. Recognovit brevique adnotatione critica instruxit Ioannes Burnet, vol. 2. Oxford: Clarendon Press, 1901.

PLATÃO. Parmênides. Tradução, apresentação e notas de Maura Iglésias e Fernando Rodrigues. São Paulo: Loyola, 2003.

\section{TEXTOS MODERNOS}

CORNFORD, F.M. Plato and the Parmenides. Parmenides' Way of Truth and Plato's Parmenides translated with an introduction and a running commentary. London: Routledge \& Kegan Paul, 1939.

FRONTEROTTA, F. MEOEXIS. La teoria platonica delle Idee e la partecipazione delle cose empiriche. Dai dialoghi giovanili al Parmenide. Pisa: Scuola Normale Superiore, 2001.

SAYRE, K. Plato's late ontology: a riddle resolved. Princeton: Princeton University Press, 1983. (1a. ed.): Parmenides Publishing, 2005. (2a. ed.)

VLASTOS, G. The Third Man Argument in the Parmenides. The Philosopbical Review, v. 63, p. 319-349, 1954.

VLASTOS, G. Addenda to the Third Man Argument: A Reply to Professor Sellars. The Philosophical Review, v. 64, p. 438-448, 1955.

VLASTOS, G. Postscript to the Third Man: a reply to Mr. Geach. The Philosophical Review, v. 65, p. 83-94, 1956.

VLASTOS, G. Plato's “Third Man” Argument (Parm. 132A1-B2): Text and Logic. The Philosophical Quarterly, v. 19, n. 77, p. 289-301, 1969.

VLASTOS, G. Platonic studies. Princeton: Princeton University Press, 1981. (1a. ed.: 1973).

VLASTOS, G. The Unity of the Virtues in the Protagoras. In: . Platonic studies. Princeton: Princeton University Press, 1981. p. 221-265.

VLASTOS, G. An ambiguity in the Sophist. In: . Platonic studies. Princeton: Princeton University Press, 1981. p. 270-322.

VLASTOS, G. A Note on "Pauline Predications" in Plato. In: . Platonic studies.

Princeton: Princeton University Press, 1981. p. 404-409. 